\title{
Dinâmica da difusão de inovações no contexto brasileiro
}

Jamila Lopes Ferreira*

Janaina Ruffoni**

Alexsandro Marian Carvalho***

\section{RESUMO}

Inovação e difusão são conceitos imbricados. Compreender a difusão de inovações significa avançar no entendimento do progresso tecnológico. Há na literatura o entendimento de que a difusão é contexto-dependente. O objetivo do estudo é analisar a difusão de inovações no Brasil, considerando suas particularidades socioeconômicas. Com dados de consumo retirados da Pesquisa Nacional por Amostra de Domicílios (PNAD) para seis produtos em diferentes períodos, estimaram-se curvas de difusão, baseadas em Rogers (1962), e calcularam-se coeficientes, conforme Bass (1969). Os principais resultados foram: o modelo mostrou-se útil para a análise da difusão no Brasil, demonstrando que as teorias de Rogers e Bass são relevantes também para este contexto; a difusão dos produtos investigados encontra-se em diferentes estágios e caracteriza-se por ser, essencialmente, um processo de imitação; e devem-se considerar as peculiaridades da difusão para a economia brasileira, pois há fatores endógenos que a tornam diferenciada.

\footnotetext{
* Universidade do Vale do Rio dos Sinos (Unisinos), São Leopoldo (RS), Brasil. E-mail: jamilalopes@yahoo.com.br

** Universidade do Vale do Rio dos Sinos (Unisinos), São Leopoldo (RS), Brasil. E-mail: jruffoni@unisinos.br

*** Universidade do Vale do Rio dos Sinos (Unisinos), São Leopoldo (RS), Brasil. E-mail: alexsandromc@unisinos.br
} 
Palavras-Chave | Difusão de Inovações; Teoria de Rogers; Modelo de Bass; Economia Brasileira

CÓdigo-JEL | O31; O33; C6

\section{Dynamics of Innovation Diffusion in Brazilian Conte}

\section{ABSTRACT}

Innovation and diffusion are imbricated concepts. Understanding diffusion of innovations means advancing knowledge about technological progress. There is in the literature the understanding that diffusion is context-dependent. The objective of this paper was to analyze the innovations diffusion in Brazil, considering their socioeconomic particularities. With consumption data collected from a national survey (PNAD) for six products in different periods, diffusion curves were estimated from Rogers (1962) and coefficients calculated according to Bass (1969). The main results were: 1) the model was useful for the diffusion analysis in Brazil, stating that Rogers and Bass are relevant theories also for this context; 2) the diffusion of the products investigated is in different stages in this economy, and is, essentially, an imitation process; and 3) should be considered the diffusion peculiarities for the Brazilian economy, since there seems to be endogenous factors that make it differentiated.

KEYWORDS | Diffusion of Innovations; Rogers Theory; Bass Model; Brazilian Economy

JEL CODE | O31; O33; C6 


\section{Introdução}

Os estudos a respeito do progresso tecnológico, que têm em Schumpeter (1912) os principais conceitos predecessores das pesquisas contemporâneas, identificam o tripé invenção-inovação-difusão como fundamental para se compreender a dinâmica da mudança tecnológica. A última etapa - a difusão - é primordial para o êxito do processo, pois, segundo Schumpeter (1912), uma inovação somente causa impacto econômico quando há uma transação comercial. Assim, é somente com a etapa de difusão que a inovação cumprirá seu papel impulsionador do desenvolvimento econômico e do progresso tecnológico.

Uma vez compreendida a relevância da difusão, seus determinantes têm sido investigados por diferentes correntes de pensamento econômico. Desde os pioneiros modelos epidemiológicos até os mais recentes modelos evolucionistas, uma gama variada de possíveis condicionantes deste processo foi elencada: riscos; incertezas; comunicação midiática e interpessoal; experiência de uso; assimetrias de informaçōes; dentre outros.

Observa-se na literatura uma discussão de que os modelos elaborados até então tiveram como amostra majoritária para análise da difusão a realidade dos países desenvolvidos e, portanto, a replicação a países periféricos pode não fazer sentido. A literatura aponta ainda para a existência de diferenças que podem afetar de forma particular a trajetória de difusão nos países periféricos, sendo algumas particularidades apontadas: as baixas renda e escolaridade; a infraestrutura inadequada; as disparidades sociais; dentre outras.

É neste contexto que se insere o objetivo do presente artigo, que se propõe a analisar o comportamento da difusão de seis produtos de uso final no Brasil, considerando as particularidades socioeconômicas brasileiras. Para tanto, foram estimados, para cada um dos seis produtos investigados, as curvas de difusão com base na teoria de Rogers (1962) e os coeficientes de inovadores (p), os coeficientes de imitadores $(\mathrm{q})$ e os pontos de saturação $(\mathrm{m})$ considerando a análise de Bass (1969). Após obtidos os resultados, os comportamentos das curvas de difusão e dos coeficientes foram analisados à luz do contexto brasileiro.

\section{Discussão teórica a respeito da difusão de inovações}

A dinâmica da inovação, conforme apontou Schumpeter já em 1912, é composta por três fases: a invenção (uma ideia potencialmente aberta para a exploração 
comercial); a inovação (exploração comercial); e a difusão (propagação de novos produtos e processos pelo mercado) (SCHUMPETER, 1912). Logo, a difusão é parte inerente ao processo de inovação e elemento essencial para que a inovação tenha, de fato, impactos econômicos e sociais.

A principal definição de difusão de inovações foi elaborada inicialmente por Rogers (1962, p. 5), que a estabeleceu como "o processo pelo qual uma inovação é comunicada através de certos canais, ao longo do tempo, entre os membros de um sistema social", sendo adotada por empresas e/ou pessoas. Hall (2004, p. 2) a define ainda como "o processo pelo qual indivíduos e firmas em uma economia adotam uma nova tecnologia ou substituem uma velha tecnologia por uma nova", com base em suas impressōes e decisōes individuais. Nesse sentido, a massificação do consumo de determinados produtos em detrimento de outros foi questionada inicialmente por Gabriel Tarde, por volta de 1903, quando indagou-se qual seria o motivo pelo qual algumas inovações se massificam pela sociedade e outras são esquecidas. Em outras palavras, o que determinaria a difusão de um novo produto/ tecnologia na sociedade?

O questionamento tornou-se problema de pesquisa de vários autores que o sucederam e que buscaram elencar possíveis condicionantes da difusão de uma nova tecnologia. Os modelos epidemiológicos foram os primeiros estudos elaborados nesse sentido e buscaram aplicar modelagens usadas para descrever a dinâmica de contágios em massa em estudos relacionados à propagação de novas tecnologias pelo lado da oferta. Isto é, os modelos buscavam compreender os determinantes da decisão da firma em incorporar, ou não, a produção de uma nova tecnologia e ofertá-la ao mercado de consumo final. O pioneirismo na aplicação de modelos deste tipo pode ser creditado a Griliches (1957), com seu modelo que descreve a adoção/difusão do milho híbrido entre os produtores dos Estados Unidos. A ideia central de seu estudo era de que a velocidade de adoção do milho híbrido dependeria essencialmente de variáveis econômicas e muito pouco de variáveis sociais (FUCK, 2013). Nesse modelo, o autor identifica que o principal determinante da difusão do milho híbrido entre os produtores foi a expectativa de lucratividade com a incorporação da inovação (VIEIRA FILHO; SILVEIRA, 2012). Desse modo, as difusōes demasiado tardias em determinadas regiōes estariam relacionadas às diferenças de rentabilidades esperadas, decorrentes da heterogeneidade das expectativas dos adotantes.

Posteriormente, Mansfield (1961) complementou o modelo abordado por Griliches (1957), acrescentando dois elementos: risco e assimetrias de informações. $\mathrm{O}$ autor identifica que, quando o número de adotantes ainda é pequeno, as assime- 
trias de informação e os riscos associados à adoção são elevados, fazendo com que a difusão ocorra de maneira lenta. À medida que cresce o número de adotantes e se acumulam experiências, bem como informações acerca da novidade, as assimetrias e os riscos se reduzem e a difusão tende a aumentar (FURTADO, 2006).

Na sequência, os modelos probit descritos por David (1969), Davies (1979) e Stoneman (1983) agregaram, ao conjunto de condicionantes apontados anteriormente, variáveis comportamentais como a heterogeneidade das firmas adotantes e suas características, entendidas por: tamanho; natureza da sua carteira de produtos e de seus processos de gestão; incertezas (que são inversamente relacionadas à aprendizagem pelo uso); objetivo de maximização de sua função utilidade; e vantagens relativas ao trade-off entre a antiga e a nova tecnologia e/ou manutenção e coexistência de ambas (FURTADO, 2006). Estes modelos buscaram, essencialmente, incluir características que conferissem heterogeneidade aos potenciais adotantes, visando inserir a imprevisibilidade de comportamentos, a qual era considerada demasiadamente estática nos modelos anteriores.

Concomitantemente, iniciou-se na literatura o estudo dos modelos de influência mista, destacando-se Bass (1969) e Metcalfe (1981), que tiveram como foco em sua investigação a adoção não mais por parte das firmas (decisão por ofertar), mas sim por parte do consumidor final (decisão por consumir). Esses autores demonstraram que a difusão deve ocorrer em dois momentos de decisão: escolha das empresas por ofertar a nova tecnologia; e escolha dos consumidores finais em adotá-la, sendo esta a etapa que finda o processo. Em seu modelo, Bass (1969) assume que os consumidores potenciais de uma inovação são influenciados por uma tendência autônoma em adotar ou não um novo produto, ou seja, adotam sem a influência do meio (os inovadores) e pela comunicação de massa e/ou relações interpessoais (os imitadores), sendo que é o efeito da ação dos imitadores que massifica a difusão da inovação (velocidade da difusão). Logo, a velocidade de adoção dos consumidores está associada ao seu padrão de comportamento, ou seja, à proporção entre inovadores e imitadores. O modelo de Bass (1969) considera que grande parte da velocidade da difusão seja proveniente da imitação e da aprendizagem dos adotantes e a outra parte seja relativamente espontânea (FIGUEIREDO, 2014).

Metcalfe (1981), à luz do modelo de Bass, definiu de forma mais objetiva a função da firma nos modelos de influência mista, ao considerar que a difusão possui comportamentos distintos para o setor produtivo (oferta) e para o consumo final (demanda). Para o lado da demanda, ele corrobora com Bass, ao apontar como determinantes para a adoção a influência do meio (ex.: comunicação "boca-a-boca" 
e interpessoal). Para o lado da oferta, o autor considera a lucratividade o principal condicionante, conforme já explorado nos modelos epidemiológicos e probit. Metcalfe (1981) faz a introdução de três componentes condicionantes à lucratividade da inovação percebida pelas empresas: preço final, custos dos insumos e tecnologias necessárias à produção.

Os mais recentes modelos investigados são os evolucionistas, nos quais destacam-se os Rosenberg (1976) e Silverberg (1988). Nesses modelos, a mutabilidade da inovação durante o processo de difusão é o principal condicionante da velocidade da difusão, que está positivamente relacionada a melhorias contínuas (inovaçōes incrementais), decorrentes da aprendizagem pelo uso (learnig-by-using). Nessa direção, Rosenberg (1976) afirma que a difusão é uma sequência de inovações incrementais, pois as melhorias que ocorrem em uma difusão em curso modelam as inovações iniciais e possibilitam sua adaptação às diferentes condiçōes de uso.

Pelo lado da oferta, Silverberg (1988) argumenta que a difusão é estimulada pela aprendizagem pelo uso, pois esse processo afeta as expectativas de rentabilidade das firmas. $\mathrm{O}$ autor acredita que quanto maior e mais conhecida for a taxa de aprendizagem do inovador, maior será a difusão entre os primeiros adotantes e, depois, entre os imitadores/seguidores. Assim, maior será a expectativa de retorno (FURTADO, 2006).

Como visto, as teorias têm dividido atençôes entre estudos voltados para o lado da oferta e da demanda. Rogers é o autor que se destaca na modelagem da dinâmica de difusão de inovações considerando o comportamento de consumidores finais. Para ele, a dinâmica da difusão depende de quatro determinantes: a inovação em si; a comunicação; o período de tempo; e o sistema social (ROGERS, 1962). No que se refere à inovação em si, cinco características percebidas pelos agentes sociais são determinantes para a adoção: vantagens comparativas da inovação adiante de produtos já existentes; compatibilidade com valores, normas e necessidades particulares; grau de complexidade da inovação em ser entendida e utilizada; possibilidade de ser testada pelos potenciais adotantes; e facilidade de avaliação da inovação após ser utilizada (ROGERS, 1962). Exceto o elemento complexidade, que é inversamente relacionado, as demais variáveis possuem relação positiva com a taxa de adoção.

No que diz respeito ao processo de comunicação, as descobertas de Rogers (1962) corroboram com Bass (1969), ao informar que podem ocorrer por meio de exposiçôes midiáticas ou trocas interpessoais, sendo ambas positivamente relacionadas à taxa de adoção. Já a variável tempo refere-se ao período no qual um indivíduo conhece a inovação, forma uma opinião sobre ela, decide por aceitá-la ou rejeitá-la, 
implementa sua decisão e confirma ou reformula sua escolha (ROGERS, 1962). Nota-se que a taxa de adoção pode impactar positiva ou negativamente, dependendo das escolhas dos consumidores.

Por fim, o sistema social corresponde aos grupos sociais nos quais os indivíduos estão invariavelmente inseridos. Estes grupos têm uma estrutura definida conforme condutas, normas e padrões de comportamento preestabelecidos, o que impõe regularidade ao comportamento individual (ROGERS, 1962). Tais hábitos facilitam ou dificultam a difusão de inovaçôes, podendo estar positiva ou negativamente relacionados à taxa de adoção. Para Rogers (1962), o comportamento e as decisões individuais são as variáveis que determinam o processo de difusão ao longo tempo.

Esta é uma das teorias mais difundidas e alguns autores apresentaram variações do modelo proposto por Rogers. Destacam-se aqui o estudo de Tellis, Stremersch e Yin (2002), para a difusão de eletrodomésticos em diferentes países europeus, no qual foi utilizado também o modelo de risco de Golder e Tellis (1997), e que se preocupa em investigar, essencialmente, o ponto de alavancagem da difusão, e o trabalho de Zettelmeyer e Stoneman (1993) sobre a difusão de CD players na Inglaterra e de carros na Alemanha, em que foram demonstrados também os modelos de Karshenas e Stoneman (1992) e de Easingwood, Mahajan e Muller (1983). No primeiro, o pressuposto de que a população mistura-se homogeneamente é eliminado e o domínio de fatores endógenos (comportamento das classes de adotantes) sobre a trajetória da difusão é relativizado (TELLIS; STREMERSCH; YIN, 2002). No segundo, os fatores exógenos não influenciam a difusão (ZETTELMEYER; STONEMAN, 1993).

\section{Difusão de inovações em economias emergentes}

Há o entendimento na literatura de que os estudos a respeito do processo de difusão precisam considerar as diferenças nas características socioeconômicas existentes nos países emergentes, quando comparados aos desenvolvidos. É necessário, portanto, aprofundar a compreensão acerca da aplicação das teorias de difusão em contextos diferentes e particulares (BATTHI; NAUMAN; EHSAN, 2013; MOLINA FILHO, 1989; NANDAKUMAR et al., 2009).

Existem constatações na literatura de elementos idiossincráticos à estrutura de países socioeconomicamente periféricos, também chamadas de "capacidade de absorção da sociedade", que tendem a atuar como barreiras significativas e parti- 
cularizar a dinâmica de difusão de inovaçôes, tornando o processo mais complexo (AUBERT, 2005; LECHMAN, 2013).

Nas décadas de 1960 e 1970, quando a maior parte dos países emergentes ainda era essencialmente agrícola, Garljart (1969, 1971, 1973 apud MOLINA FILHO, 1989) destacou três determinantes: ignorância; impotência; e não disposição. Os dois primeiros referem-se à falta de capacidades cognitivas para adoção de novas tecnologias e o último correspondem à pré-indisposição decorrente de valores culturais intrínsecos de alguns países. A falta de cognição é decorrente do baixo nível de escolaridade de grande parte da população, o que reduz o nível de renda e o poder aquisitivo no geral e provoca a insuficiência do poder de compra para adotar tecnologias de alto valor, ou até mesmo de baixo custo, de boa parte das populações residentes em países em desenvolvimento (NANDAKUMAR et al., 2009; WILSON, 2000).

Molina Filho (1989, p. 106) destaca a disparidade entre regiōes, pois, "O poder, a riqueza e a informação estão concentrados nas mãos de poucas pessoas e grupos", o que influencia no potencial de adoção de novas tecnologias, uma vez que restringe o acesso a camadas sociais específicas. Boalch (1997), em seu estudo voltado para difusão da internet, revela a existência de infraestrutura física, de telecomunicações e de transportes precária e desigualmente concentrada nas grandes metrópoles, o que provoca disparidades de acesso a produtos e informação. A questão da infraestrutura precária e desigual é corroborada por Aubert (2005) e por Soares (2011), que afirmam existir em países de periferia uma variedade de organizaçōes e indivíduos que não possuem acesso à infraestrutura mínima, como na questão de saneamento básico, pois, quando grande parte do mercado interno está sujeita a condições inadequadas de nutrição e saúde, torna-se complicada a propagação em massa de inovações.

Aubert (2005, p. 2) acrescenta ainda que o clima inovativo nestes países é "naturalmente problemático", sendo substancialmente dificultado pela deficiência na interação do tripé "conhecimento técnico - setor privado - setor público". Isto deve-se à presença de baixos níveis educacionais e a precárias condições do ambiente de negócios e governamental, agravado pela forma burocrática com a qual governos de países periféricos lidam com questões relativas à inovação, como atividades de P\&D, patentes e abertura de novas empresas (AUBERT, 2005; SOARES, 2011).

De maneira resumida, as características inerentes a países periféricos são:

- baixos níveis de escolaridade, impactando em capacidades cognitivas e conhecimentos técnicos insuficientes; 
- baixo nível de renda e de poder aquisitivo;

- disparidades regionais de renda e sociais;

- infraestruturas física, de transportes e de comunicação precárias;

- assimetrias de informações;

- burocracia excessiva e arranjos institucionais falhos;

- disparidades de acesso a saneamento básico.

\section{Método}

O método aplicado refere-se à estimação de curvas de difusão para cada produto de uso final selecionado, conforme Rogers e seu conceito de curva S. Para Rogers (1962), a adoção de inovações assume uma forma de S, conforme exposto da Figura 1 , pois a adoção transcorre entre grupos de adotantes, quais sejam:

- inovadores: primeiros a adotar (sem influência do meio social);

- adotantes iniciais: integram o grupo dos primeiros adotantes (junto aos inovadores);

- maioria inicial: a decisão pela adoção é relativamente mais tardia (necessitam de informaçōes);

- maioria tardia: adotam por pressão do meio social;

- retardatários: adotam muito tempo depois do lançamento (após divulgação de considerável quantidade de informações acerca da inovação).

FIGURA 1

Curva de difusão de inovaçôes

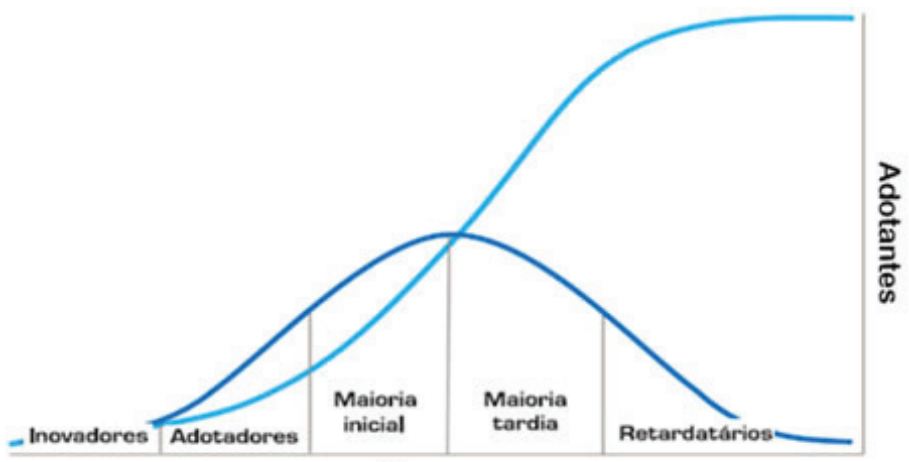

Tempo

Fonte: Elaborado pelos autores, com base em Rogers (1962). 
O formato da curva é derivado do comportamento da adoção, que aumenta lentamente no início, quando apenas os inovadores a adotam, e acelera ao atingir os adotantes iniciais e a maioria inicial, o que representa a metade dos indivíduos previstos no sistema. Após, aumenta a uma taxa mais lenta, alcançando a maioria tardia e retardatária (ROGERS, 1962 apud NOGUEIRA-CAMPOS; GAMA; PINTO, 2008).

O conceito de curva S de Rogers foi aplicado no estudo aqui apresentado, pois, conforme o autor, teria aplicação universal para todos os produtos e contextos e não estaria vinculado ao tipo de inovação estudada, mas sim ao comportamento de potenciais adotantes (ROGERS, 1962). É possível, portanto, que ocorram variações na velocidade e na inclinação das curvas, visto que algumas inovações podem se difundir rapidamente, gerando uma curva íngreme, enquanto outras têm uma taxa mais lenta de adoção, desenhando uma curva de inclinação mais gradual, mas no formato $S$.

Vale ressaltar, entretanto, que o modelo de Rogers tem sido utilizado em diferentes estudos, sendo que a verificação de sua validade se confirma incondicionalmente em alguns casos, mas, em outros, parcialmente. Um estudo em que o modelo demonstrou aplicabilidade plena foi o da adoção de inovações por enfermeiras em seu local de trabalho, no qual os resultados corroboraram as cinco características apontadas por Rogers (LEE, 2004). De maneira distinta, investigaçôes que não encontraram identificação plena com o modelo de Rogers foram: o estudo epistemológico aplicado às configurações atuais da comunicação social (FILHO; GOULART; CAPRINO, 2007); processo de difusão bidimensional, que combina disposição do potencial adotante e preço (KAPUR et al., 2010); difusão de sistemas fotovoltaicos (KONZEN, 2014); e processo de disseminação de experiências inovadoras de gestão pública (PAULICS, 2003).

No presente trabalho foi utilizada, de forma complementar, a quantificação matemática para a teoria de Rogers proposta por Bass (1969). Essa considera uma população de tamanho constante e binária, dividida entre adotantes e não adotantes, misturados de maneira homogênea e que interagem em um tempo contínuo. ${ }^{1}$ De forma semelhante a Rogers, Bass (1969) assume que a difusão acontece por meio de duas categorias de agentes: inovadores, que adotam as inovações independentemente de decisōes dos outros agentes; e imitadores, que têm sua decisão influenciada

1 Valores que podem assumir qualquer quantia na reta de números reais, não sendo constituídos somente de números inteiros. Considera-se o "tempo" uma variável contínua, pois pode ser medido em anos, dias, horas, fraçōes de segundos, podendo os valores serem fracionados. 
pela pressão do meio social. Assim como Rogers, a curva de difusão de inovações derivante do Modelo de Bass assume um formato S, pois o comportamento será impactado pela velocidade com a qual as inovações são adotadas pelos dois grupos. Com base nisso, o autor propôs a seguinte equação:

$$
n(t)=\frac{d N(t)}{d t}=p[m-N(t)]+\frac{q}{m} N(t)[m-N(t)]
$$

Onde $p$ é o coeficiente de inovadores; $q$ é o coeficiente de imitadores; $m$ é o número final de adotantes ou o ponto onde a difusão estará completa (ponto de saturação); $N(t)$ é a fração de adotantes totais em cada instante de tempo e $n(t)$ é a taxa de variação ou o número de novos adotantes em cada período. O termo $p[m-N(t)]$ representa as adoçôes dos inovadores e o termo $\frac{q}{m} N(t)[m-N(t)]$ corresponde às adoções dos imitadores. A equação (1) é uma equação diferencial ordinária de primeira ordem. Desse modo, dada a condição inicial $N(0)=N_{0}$, a sua solução é obtida via integração imediata e está exposta a seguir:

$$
N(t)=\frac{m\left(-m+\mathrm{N}_{0}\right) e^{-(p+q) t} p+m\left(m p+\mathrm{N}_{0} q\right)}{\left(m-\mathrm{N}_{0}\right) q e^{-(p+q) t}+\left(m p+\mathrm{N}_{0} q\right)}
$$

A equação (2) demonstra o número de adotantes em cada instante do tempo. Foi utilizada com auxílio do software Wolfram Mathematica, para estimar os parâmetros $p, q$, e $m$ é a curva de ajuste do conjunto de dados de cada produto. São números relativos e sua relação determina o formato das curvas de difusão (curva de ajuste) estimada.

O modelo de Bass acompanha adequadamente a curva de difusão para uma diversidade de tecnologias (SULTAN; FARLEY; LEHMANN, 1990). Em geral, o modelo é bem-sucedido em explicar a adoção de tecnologias que são conduzidas por um processo de contágio de influências internas (contato entre os indivíduos) e externas (como por exemplo, a ação da mídia) (GOLDENBERG et al., 2000). No entanto, na literatura encontram-se discussões acerca das limitações do modelo, tais como: poder preditivo (VAN DEN BULTE; LILIEN, 1997; KOHLI; LEHMANN, 1999); poder explicativo (STRANG; MACY, 2001; MAIENHOFER; FINHOLT, 2002; HOHNISCH; PITTNAUER; STAUFFER, 2008); heterogeneidade da população (BEMMAOR; LEE, 2002; EMMANOUILIDES; DAVIES, 2007; RAHMANDAD; STERMAN, 2008); e processos sociais (VAN DEN BULTE; STREMERSCH, 2004). 


\subsection{Base de dados}

Para avaliar o processo de difusão neste trabalho, foi utilizada uma série histórica de dados da Pesquisa Nacional por Amostra de Domicílios (PNAD). Os dados representam o percentual anual de domicílios que declararam possuir bens de uso final selecionados ${ }^{2}$ nos anos de observação, conforme disponibilidade da pesquisa, a saber:

- geladeira (1981 a 2014);

- máquina de lavar roupas (1992 a 2014);

- televisão (1992 a 2014);

- computador (2003 a 2014);

- computador com internet (2003 a 2014); e

- celular (2003 a 2014).

Os seis produtos foram agrupados em dois grupos: eletrodomésticos (os três primeiros) e Tecnologias de Informação e Comunicação (TICs) (os três últimos). Os seis produtos foram selecionados considerando o universo de bens duráveis investigados pela PNAD e os conjuntos de dados que apresentaram adoção ano após ano, para que o modelo pudesse capturar o processo de difusão. Além disso, para que a dinâmica apresentada fosse a mais completa possível, foram selecionados os seis produtos cuja série histórica dispunha de mais observações, levando em conta a introdução do produto no mercado. Por este motivo, as TICs selecionadas possuem séries históricas mais curtas, ao passo que o conjunto de eletrodomésticos possui séries mais longas. As curvas de difusão obtidas são aquelas que melhor se ajustam ao conjunto dos dados coletados. Para tanto, foi usado o método de mínimos quadrados $^{3}$ e as curvas foram elaboradas com o software Origin 8.

\subsection{Estimativas}

Foram estimadas as velocidades médias ( $v$ ) de difusão de cada produto, conforme equação (3):

$$
v=\frac{1}{T} \sum_{i=1}^{T} \frac{N_{t+1}-N_{t}}{\Delta t}
$$

2 Série de dados por produto disponível em: <http://www.sidra.ibge.gov.br/pnad/pnadpb.asp?o=3\&i=P e em http://seriesestatisticas. ibge.gov.br/lista_tema.aspx?op=0\&de=14\&no=6>.

3 Método que minimiza a soma dos quadrados das diferenças entre os valores da curva de ajuste e os dados empíricos em cada ponto. 
Onde $T$ é o intervalo total de tempo da série; o termo $\frac{N_{t+1}-N_{t}}{\Delta t}$ corresponde à taxa de adoção por unidade de tempo, já que $N_{t}$ é o número de adotantes no tempo $t$, e $N_{t+1}$ é o número de adotantes no tempo imediatamente posterior $(t+1)$; e $v$ representa a média das taxas marginais de adoção obtidas na razão entre $N_{t}$ e $N_{t+1}$, ou seja, o percentual médio de novos adotantes por ano.

Com o intuito de verificar a aplicabilidade do modelo e da curva estimada aos dados, foram estimados o erro médio $\left\langle N_{E}\right\rangle$ e o desvio padrão $\left\langle\sigma_{N_{E}}\right\rangle$, conforme segue:

$$
\begin{gathered}
\left\langle N_{E}\right\rangle=\frac{1}{T} \sum_{k=1}^{T}\left|N_{E}(k)-N_{A}(k)\right| \\
\sigma_{N_{E}}=\sqrt{\frac{1}{T-1} \sum_{k=1}^{T}\left(N_{E}(k)-\left\langle N_{E}\right\rangle\right)^{2}}
\end{gathered}
$$

Onde $N_{E}(k)$ é o número de adotantes no instante $k$, conforme dados empíricos; $N_{A}(k)$ refere-se ao número de adotantes no instante $k$, baseado nos dados que deram origem à curva de ajuste; e $T$ é o intervalo total de tempo observado na série temporal. $\mathrm{O}$ erro médio representa a distância entre o dado empírico e a curva de ajuste, e o desvio padrão, por sua vez, mede o volume, em percentual, de dados que não estão sendo abrangidos pela curva de ajuste (pontos fora da curva).

\section{Resultados e análises}

As curvas apresentadas a seguir evidenciam o comportamento parcial da adoção; as séries históricas completas não foram analisadas devido à indisponibilidade de dados. Contudo, a partir da relação entre coeficiente de inovadores $(p)$ e coeficiente de imitadores $(q)$ foi possível inferir sobre o formato integral da curva, pois: a) quanto mais próximo de zero for $p$ ou quanto menor ele for em relação à $q$, mais formato de $S$ terá a curva de difusão; b) para o inverso, mais côncava será a curva de difusão. O ponto de saturação $(m)$ comparado ao último ponto das curvas, por sua vez, indica em qual segmento encontra-se a difusão.

Após os cálculos, as melhores curvas de ajuste para o grupo de eletrodomésticos estão expostas na Figura 2. 
FIGURA 2

Curvas de difusão e coeficientes encontrados para eletrodomésticos Brasil - 1981-2014
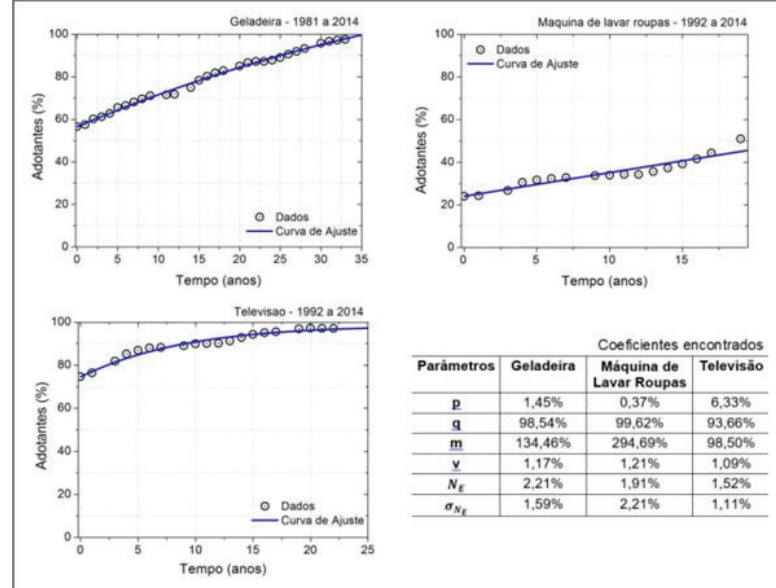

Fonte: IBGE. Pesquisa Nacional por Amostra de Domicílios - PNAD. Elaboração dos autores.

Os coeficientes expostos na tabela da Figura 2 apontam que a relação entre $p$ e $q$ atendem à condição 'b' citada no início do capítulo, pois o coeficiente de imitadores $(q)$ é muito superior ao de inovadores $(p)$, o que indica que as curvas de difusão dos três produtos possuem formato $S$. Comparando o último ponto da curva de difusão de cada produto com seus respectivos pontos de saturação $(m)$, observa-se que os produtos geladeira e televisão encontram-se próximos da difusão completa (no segmento final da curva), enquanto máquina de lavar roupas está em estágio intermediário. As velocidades médias $(v)$ se assemelham (todas em torno de 1\%).

Para compreender os resultados, é preciso buscar informações a respeito do contexto histórico brasileiro. A introdução dos três produtos data da década de $1950,{ }^{4}$ período em que o Brasil vivenciava a industrialização e urbanização por meio do processo de substituição de importações e uma forte abertura ao capital externo para desenvolvimento das indústrias nacionais (dentre elas, a de bens duráveis) (LIMA, 2011). O setor industrial recebia estímulos que parecem ter favorecido a difusão da geladeira e da televisão, em detrimento da máquina de lavar roupas, tornando seu

4 Em 1950 entrou em operação a Consul, primeira fábrica de geladeiras em larga escala do Brasil, na cidade de Joinville-SC (CONSUL, 2015); em 1951, o primeiro aparelho de televisão foi montado no Brasil (TELEVISOR...[2017?]); e em 1959, foi fabricada pela Brastemp a primeira lavadora de roupas do Brasil, porém o uso do produto só foi intensificado a partir da década de 1980 (WHIRLPOOL, 2017). 
coeficiente de inovadores $(p)$ menor. É razoável inferir, portanto, que alguns fatores tenham condicionado a preferência dos indivíduos.

A estrutura econômica brasileira na década de 1950 ainda era essencialmente voltada para a agricultura, quadro que começou a ser transformado com o desenvolvimento do setor industrial (PEREIRA, 1977). Tal estrutura incorria em baixa renda, baixo nível de educação e predominância de infraestrutura precária: a renda per capita do brasileiro (em dólares) era de cerca de US\$200,00 (comparativamente, em 2014 correspondia a aproximadamente US\$11.000,00, segundo relatório do Banco Mundial), o analfabetismo atingia cerca de 50\% da população e apenas 36\% dos habitantes residiam em área urbana, com condiçôes de acesso à infraestrutura mais adequada (LOURENÇO FILHO apud BRASIL, 2016). A renda baixa provoca restrição orçamentária, diante da qual os indivíduos optam primeiro pelos bens de necessidade primária ou que não possuem substitutos diretos - caso da geladeira e da televisão - e somente depois por outros bens. $\mathrm{O}$ efeito substituição fica mais evidente quando se comparam as velocidades de difusão pós anos 2000: embora semelhantes ao considerar todo o período, as velocidades médias se diferem sensivelmente a partir de 2004, quando a máquina de lavar roupas passa a ser adotada com mais rapidez (2,30\% de novos domicílios adotantes ao ano) do que a geladeira e a televisão $(0,93 \%$ e $0,64 \%$ de novos domicílios adotantes, respectivamente). Nesse sentido, Matsuyama (2002, p. 6) ressalta que:

[...] existem complementaridades de demanda entre bens de primeira necessidade e bens de prioridade mais reduzida. À medida que as despesas com os itens essenciais declinam, os itens menos essenciais tornam-se acessiveis, o que permite que os domicílios possam mover-se para baixo em suas listas de compras.

É possível deduzir que o baixo nível de educação tende a prejudicar a propensão a adquirir produtos mais tecnológicos, considerando que máquinas de lavar roupas eram tecnologias com utilização relativamente mais sofisticada, se comparada ao uso da televisão e da geladeira, além de exigirem também maior infraestrutura (como energia elétrica e água encanada). Nesse sentido, é coerente inferir que a infraestrutura rural dificultava a massificação de informaçōes acerca do produto e o acesso a ele.

Deve-se ressaltar o tempo de difusão percorrido pelos produtos: introduzidas no mercado há, pelo menos, 60 anos, geladeira e televisão mostraram-se próximas da difusão completa em 2014; já a máquina de lavar roupas, mesmo sendo um produto amplamente utilizado e conhecido atualmente, estava difundida em apenas metade 
dos domicílios em 2014. No caso da máquina de lavar roupas, parece razoável supor que ainda estejam implícitas questôes de renda, uma vez que o conhecimento mais elevado atualmente, em relação ao passado, acerca do produto (aprendizagem pelo uso) não se torna condicionante suficiente para a adoção. Também existe a questão da manutenção de disparidades de infraestrutura urbana (concentrada nos grandes centros e polos econômicos, especialmente saneamento básico e abastecimento de água e energia elétrica). Conforme dados do último Censo, nas regiōes Norte e Nordeste cerca de $75 \%$ de sua população reside em área urbana, percentual que alcança 90\% no Sudeste; e cerca de 76\% do Nordeste e 54\% da região Norte dispóem de água encanada, contra 90\% da região Sudeste (IBGE, 2010).

Para geladeira e televisão, o longo período percorrido (mais de 60 anos) pode ser entendido pelo fato de boa parte do processo de difusão ter ocorrido em uma estrutura social e econômica em transição de rural para urbana, e em uma economia que recém abria-se ao capital externo e iniciava seu processo de desenvolvimento industrial (LIMA, 2011; PEREIRA, 1977). "A difusão de bens de consumo duráveis costuma ocorrer em ondas, começando das camadas de renda mais alta e progressivamente se espraiando para os grupos de menor poder aquisitivo." (EARP; PAULANI, 2014, p. 473).

Constata-se também que, pelos resultados estimados para o erro médio $\left\langle N_{E}\right\rangle$ e o desvio padrão $\left\langle\sigma_{N_{E}}\right\rangle$ - todos em torno de $1 \%$ a $2 \%$-, a curva de ajuste e o modelo usado se mostraram aplicáveis ao conjunto de dados analisados.

Em relação ao grupo das TICs, a Figura 3 apresenta as melhores curvas geradas pelos cálculos.

Ao analisarmos os coeficientes, observa-se que a relação entre $(p)$ e $(q)$ atende à condição 'b' citada no início do capítulo, pois o coeficiente de imitadores $(q)$ é muito superior ao de inovadores $(p)$, indicando que as curvas de difusão destes produtos possuem formato $S$. Comparando o último ponto da curva de difusão de cada produto com seus respectivos pontos de saturação $(m)$, constata-se que o celular encontra-se próximo da difusão completa (no segmento final de suas curvas de difusão), enquanto o computador e o computador com internet estão em estágio intermediário. As velocidades médias $(v)$ desses dois últimos produtos se assemelham, em torno de $2 \%$, enquanto o celular apresentou velocidade maior, mais de 4\%, para os coeficientes de inovadores. Identifica-se a predominância do celular em detrimento do computador e do computador com acesso à internet. 
FIGURA 3

Curvas de difusão e coeficientes encontrados para TICs

Brasil - 2003-2014
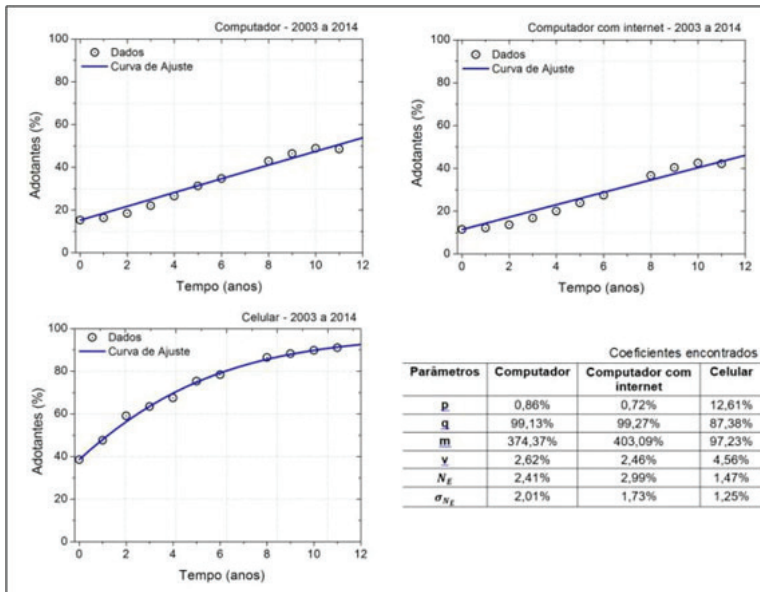

Fonte: IBGE. Pesquisa Nacional por Amostra de Domicílios - PNAD. Elaboração dos autores.

Para compreender os possíveis motivos dos resultados é preciso recorrer, novamente, a características do contexto brasileiro. Os computadores para uso pessoal foram surgindo no Brasil lentamente a partir de 1950, sendo inicialmente adquiridos por entidades do governo e corporaçóes de maior porte, já que a tecnologia era importada e de custo elevado. O primeiro computador produzido no Brasil data do início da década de $1980,{ }^{5}$ quando passou a ser de acesso do grande público. A internet acompanhou este movimento, chegando ao Brasil em meados de 1990, ${ }^{6}$ sendo que seu acesso foi expandido ao grande público a partir de 1995. O telefone celular foi lançado no Brasil no início dos anos $1990^{7}$ e teve sua adoção massificada após a abertura comercial do governo Fernando Collor (UNIVERSIDADE ESTADUAL DE MARINGÁ, [2017?]).

Além da restrição de uso inicial, a preferência dos indivíduos pode ter ligação com preços, características intrínsecas e propósitos dos produtos (relações custo-benefício). Percebe-se, pelo contexto de introdução dos produtos nos mercados,

5 Em 1979, foi criada a Secretaria Especial de Informática (SEI). Em seguida, foi lançado no mercado o primeiro computador totalmente produzido no Brasil, desde o projeto ao produto final: o Cobra 530 (FERRARI, 2013).

6 A internet foi implementada para uso no Brasil em meados dos anos 1990, sendo seu acesso restrito ao meio acadêmico e empresas. Em meados de 1995, seu acesso foi disponibilizado ao grande público (HISTÓRIA..., [2017?]).

7 A primeira rede de telefonia celular do Brasil foi lançada pela Telerj, na cidade do Rio de Janeiro em 1990 (HISTÓRIA..., [2017?]). 
que o computador inicialmente teve propósito de facilitar as atividades de controle e gestão das grandes corporações e do governo. Logo, seu custo era extremamente elevado, restringindo a adoção pelo grande público. Em termos do valor monetário da época, o preço de um computador se equivalia à compra de um carro (HAMANN, 2011). O advento da internet iniciou também restrito à utilização em universidades e centros de pesquisa. Quando disponibilizada ao público geral, sua conectividade era precária, via conexão discada, e sua contratação condicionada ao pagamento mensal de uma taxa extra. Esse consiste no produto de valor mais elevado dentre os três do grupo, pois depende do custo do computador acrescido do serviço de internet.

Em relação ao celular, percebe-se que este foi agregando funções de diferentes produtos. Assim, faz sentido supor que, diante de restrições orçamentárias, a demanda concentre-se no produto que, na percepção dos usuários, parece apresentar o melhor custo-benefício. Existem também outros elementos que indicam ter relação com a adoção do celular em detrimento do computador (sem e com acesso à internet): o uso do celular parece exigir menor capacidade cognitiva; com a sobreposição de funcionalidades e utilidades, entende-se que o celular e o computador tornaram-se, para determinados grupos sociais e certas funções, produtos substitutos; por fim, é necessário considerar a diferença de preço entre computadores e celulares, o que influencia a tomada de decisão pela adoção.

Em relação às velocidades médias, é relevante realizar uma comparação com os resultados obtidos para o grupo de eletrodomésticos. A adoção dos três produtos das TICs precisou de um intervalo de tempo de aproximadamente 20 anos para atingir os mesmos patamares que os eletrodomésticos, que necessitaram de cerca de 60 anos (o celular encontra-se quase totalmente difundido, assim como geladeira e televisão, ao passo que computador, computador com internet e máquina de lavar roupas estão em estágios intermediários). Conforme já analisado, o fato tem relação com os contextos econômicos nos quais os produtos foram inseridos: enquanto os eletrodomésticos surgiram em um mercado que atravessava um período de transição rural-urbana e de desenvolvimento do setor industrial, os produtos do grupo das TICs tiveram sua difusão majoritariamente ocorrida em uma economia mais estável e aberta ao mercado externo (período pós-Plano Real). Além disso, é preciso destacar que, no processo de difusão das TICs, costumam ocorrer os "efeitos de redes". Tal efeito acontece quando o valor de um produto percebido pelo potencial adotante está positivamente correlacionado ao número de usuários, pois sua utilização forma uma "rede", ou seja, seu uso pressupõe que outros usuários também o utilizem. Nesse sentido, um novo usuário estará acrescentando valor ao produto, já que estes terão 
uma pessoa a mais para formar a rede. Com isso, à medida que a rede vai crescendo, novos usuários são atraídos (SAMPAIO; HATEM, 2010).

Para concluir, a partir dos resultados estimados de erro médio $\left\langle N_{E}\right\rangle$ e desvio padrão $\left\langle\sigma_{N_{E}}\right\rangle$ - em torno de $1 \%$ a $3 \%$-, constata-se que a curva de ajuste estimada e o modelo também foram aplicáveis ao conjunto de dados dos produtos TICs.

\section{Considerações finais}

Entende-se que a pesquisa contribuiu em duas linhas principais: demonstrar que o modelo matemático utilizado foi útil para analisar o processo de difusão de bens finais; e proporcionar uma análise empírica da difusão pelo lado da demanda, contextualizado para a economia brasileira.

Com este trabalho foi possível verificar que a utilização da teoria de Rogers e do modelo de Basse se mostrou útil para representar o comportamento da difusão de diferentes tecnologias em diferentes períodos de tempo no Brasil. Isso porque os parâmetros $q$ se mostraram superiores aos parâmetros $p$ em todos os casos, sugerindo o formato $S$ das curvas de difusão, de forma menos ou mais acentuada, corroborando o formato universal sugerido por Rogers.

No que diz respeito à análise empírica, destaca-se que, para os seis bens de consumo final investigados, o exercício matemático apontou para uma dinâmica de difusão conduzida pelo comportamento dos "imitadores", pois o coeficiente deste grupo $(q)$ se mostrou muito superior ao coeficiente de inovadores $(p)$. Assim, a maior parcela dos adotantes das seis tecnologias foi composta de imitadores, tendo este grupo papel essencial no processo de difusão. Ou seja, a dinâmica encontrada evidencia que a difusão das tecnologias investigadas no Brasil é, na realidade, um processo de imitação.

Outra constatação foram os diferentes estágios de difusão das tecnologias estudadas. As curvas identificadas são parciais, não evidenciando a trajetória total de adoção, representando somente alguns segmentos de uma curva $S$ (não capturada na sua totalidade por restrição de dados). Nesse sentido, ao se comparar os pontos em que a difusão estará concluída (ver Figuras 2 e 3), pode-se constatar que, das seis tecnologias analisadas, três informam estar em um estágio final de difusão (da metade para o fim da curva) e três estão em estágio intermediário (do início para a metade da curva). No primeiro grupo estão telefone celular (adoção de 91,08\% dos domicílios e $m$ de 97,23\%), televisão (97,14\% e $m$ de 98,50\%) e geladeira $(97,56 \%$ e $m$ de $134,46 \%)$; esses três produtos também apresentaram coeficientes 
de inovadores $(p)$ acima de $1 \%$. Já o segundo grupo é composto por máquina de lavar roupas (adoção de 58,68\% dos domicílios e $m$ de 294,69\%), microcomputador $(48,54 \%$ e $m$ de $374,37 \%)$ e microcomputador com acesso à internet $(42,09 \%$ dos domicílios e $m$ de 403,09\%); o coeficiente de inovadores ( $p$ ) nestas três tecnologias é inferior a $1 \%$.

Outro ponto é a verificação de que a abordagem da difusão com base em Rogers e Bass também se aplica ao contexto brasileiro, ao ser identificado um comportamento da difusão caracterizado por uma curva S. Mas, para além disso, os resultados indicam a importância de considerar as idiossincrasias do contexto brasileiro para compreender o comportamento da difusão, pois, por exemplo, as velocidades de adoção mostram-se diferentes para os produtos estudados.

Assim, tecnologias, mesmo que já maduras, testadas e difundidas em países desenvolvidos, quando inseridas em países emergentes, passam a sofrer a influência de características endógenas destas economias. A dinâmica encontrada no trabalho corrobora também a relação apontada pela literatura entre difusão de inovações e o subdesenvolvimento. Os resultados do estudo aqui apresentado reforçam a percepção de que um dos fatores que realimentam o subdesenvolvimento é o próprio subdesenvolvimento, pois a inovação é elemento-chave para o desenvolvimento socioeconômico e a difusão de inovações é parte integrante deste processo. Assim, uma economia que apresenta dificuldades em difundir novos produtos, devido à sua situação de subdesenvolvimento, inibe a atividade inovativa, gerando um circuito vicioso.

As considerações apresentadas limitam-se a um modelo matemático em que se supõem adotantes uniformemente misturados, cujo comportamento (inovador ou imitador) não se altera no tempo. Por um lado, tais pressupostos são úteis para investigar a dinâmica da adoção das tecnologias no âmbito de um indivíduo que possui predisposição à adoção, bem como as possíveis causas para o comportamento geral da difusão. Por outro, fragilizam-se na detecção dos determinantes econômicos específicos que potencializam a adoção de uma tecnologia por um agente e no entendimento do papel da oferta e demanda das tecnologias em sua disseminação.

A fim de complementar os achados deste estudo, sugere-se a realização de análises econométricas para investigar os fatores determinantes para um indivíduo adquirir uma tecnologia, tais como níveis de renda, escolaridade, distribuição demográfica dos adotantes, entre outros. 


\section{Referências bibliográficas}

AUBERT, J-E. Promoting innovation in developing countries: a conceptual framework. Washington DC: World Bank Institute, 2005. (World Bank Policy Research Working Paper, n. 3554). Disponível em: <openknowledge.worldbank.org/bitstream/handle/10986/8965/ wps3554.pdf?sequence=1\&isAllowed=y >. Acesso em: 06 jun. 2015.

BASS, F. A new product growth for model consumer durables. Management Science, Maryland, v. 15 , n. 8 , p. $215-227,1969$.

BATTHI, S. H.; NAUMAN, S.; EHSAN, N. The dominant patterns of innovation. Journal of Quality and Technology Management, Islamabad, v. 9, n. 1, p. 31-55, 2013.

BEMMAOR, A. C.; LEE, J. The impact of heterogeneity and ill-conditioning on diffusion model parameter estimates. Marketing Science, Maryland, v. 21, n. 2, p. 209-220, 2002.

BOALCH, G. A preliminary model of internet diffusion within developing countries. In: THIRD AUSTRALIAN WORLD WIDE WEB CONFERENCE. Proceedings... Queensland, Austrália, 1997. Disponível em: <http://ausweb.scu.edu.au/aw97/papers/boalch/paper. htm>. Acesso em: 06 jun. 2015.

BRASIL. Ministério da Educação. Sistema Educativo Nacional de Brasil. Portal do MEC, 2016.

CONSUL. Quem é a Consul. 2015. Disponível em: <https://www.consul.com.br/sobreaconsul/>. Acesso em 18 ago. 2017.

DAVID, P. A. A contribuition to the theory of diffusion. 1. ed. Stanford: Stanford University, 1969.

DAVIES, S. The diffusion of process innovations. 1. ed. Cambridge: Cambridge University Press, 1979.

EARP, F. de S.; PAULANI, L. M. Mudanças no consumo de bens culturais no Brasil após a estabilização da moeda. Nova Economia, Belo Horizonte, v. 24, n. 3, p. 469-490, 2014.

EMMANOUILIDES C. J.; DAVIES, R. B. Modelling and estimation of social interaction effects in new product diffusion. European Journal of Operational Research, v. 177, n. 2, p. 1253-1274, 2007.

FERRARI, C. G. M. R. S. O surgimento da informática e sua chegada ao Brasil. Portal Educação, 2013. Disponível em: <https://www.portaleducacao.com.br/conteudo/artigos/ iniciacao-profissional/o-surgimento-da-informatica-e-sua-chegada-ao-brasil/47410>. Acesso em: 20 jul. 2017. 
FIGUEIREDO, J. C. B. de. Modelo de difusão de Bass: uma aplicação para a indústria de motocicleta no Brasil. 1. ed. São Paulo: Centro de Altos Estudos da ESPM, 2014.

FILHO, G. G.; GOULART, E. E.; CAPRINO; M. P. Difusão de inovações: apreciação crítica dos estudos de Rogers. Revista FAMECOS, Porto Alegre, n. 33, p.41-47, 2007.

FUCK, M. P. Ideias fundadoras. Revista Brasileira de Inovação, Campinas, v. 12, n. 2, p. 241-250, 2013.

FURTADO, A. Difusão tecnológica: um debate superado? In: PELAEZ, V.; SZMRECSÁNYI, T. Economia de inovação tecnológica. 1. ed. São Paulo: Hucitec, 2006.

GOLDENBERG, J.; LIBAI, B.; SOLOMON, S.; JAN N, S. D. Marketing percolation. Physical A: Statistical Mechanics and its Applications, v. 284, n. 1-4, p. 335-347, 2000.

GRILICHES, Z. Hybrid corn: an exploration in the economics of technological change. Econometrica, New York, v. 25, n. 4, p. 501-522, 1957.

HALL, B. H. Innovation and diffusion. Cambridge, MA: The National Bureau of Economic Research, 2004. (Working paper, n. 10212). Disponível em: <http://www.nber.org/papers/ w10212.pdf>. Acesso em: 05 maio 2015.

HAMANN, R. O preço da informática: o computador já custou mais que um carro. Tecmundo, 2011. Disponível em: <https://www.tecmundo.com.br/infografico/9210-o-precoda-informatica-o-computador-ja-custou-mais-que-um-carro.htm>. Acesso em: 20 jul. 2017. HISTÓRIA da Internet no Brasil. Wikipedia, a enciclopédia livre, [S.l., 2017?]. Disponível em: <https://pt.wikipedia.org/wiki/Hist\%C3\%B3ria_da_Internet_no_Brasil>. Acesso em: 20 ago. 2017.

HOHNISCH, M.; PITTNAUER, S.; STAUFFER, D. A percolation-based model explaining delayed takeoff in new-product diffusion. Industrial and Corporate Change, Oxford, v. 17, n. 5, p. 1001-1017, 2008.

IBGE - Instituto Brasileiro de Geografia e Estatística. Censo Demográfico 2010. Rio de Janeiro, 2010. Disponível em: <http://www.sidra.ibge.gov.br/bda/popul/default.asp?z=t\&o=25\&i=P>. Acesso em: 29 maio 2016.

Pesquisa Nacional por Amostra de Domicilios (PNAD). Rio de Janeiro, [2016?]. Disponível em: <http://www.sidra.ibge.gov.br/pnad/pnadpb.asp?o=3\&i=P> e <http://seriesestatisticas.ibge.gov.br/lista_tema.aspx?op=0\&de=14\&no=6>. Acesso em: 25 mar. 2016.

KAPUR, P. K.; SINGH, O.; CHANDA, U.; BASIRZADEH, M. Determining adoption pattern with pricing using two-dimensional innovation diffusion model. Journal of High Technology Management Research, v. 21, p.136-146, 2010. 
KOHLI, R.; LEHMANN D. R.; PAE, J. Extent and impact of incubation time in new product diffusion. Journal of Product Innovation Management, Hanover, v. 16, n. 2, p. 134144, 1999.

KONZEN, G. Difusão de sistemas fotovoltaicos residenciais conectados à rede no Brasil: uma simulação via modelo de Bass, 2014, 109 f. Dissertação (Mestrado em Ciências) - Instituto de Energia e Ambiente da Universidade de São Paulo, São Paulo, 2014.

LECHMAN, E. ICTs diffusion trajectories and economic development - an empirical evidence for 46 developing countries. Gda sk, Polônia, 2013 (GUT FME Working Paper Series A, n. 18/2013). Disponível em: <http://www.researchgate.net/profile/Ewa_Lechman/publication/259602695_ICTs_DIFFUSION_TRAJECTORIES_AND_ECONOMIC_DEVELOPMENT_AN_EMPIRICAL_EVIDENCE_FOR_46_DEVELOPING_COUNTRIES/ links/00b7d52cdcfdd236c8000000.pdf>. Acesso em: 05 maio 2015.

LEE, T-T. Nurses' adoption of technology: application of Rogers' innovation-diffusion model. Applied Nursing Research, v. 17, n. 4, p. 231-238, 2004.

LIMA, S. de C. Da substituição de importações ao Brasil potência: concepções do desenvolvimento 1964-1979. Revista Aurora, São Paulo, v. 5, n. 7, p. 34-44, 2011.

MAIENHOFER, D.; FINHOLT, T. Finding optimal targets for change agents: a computer simulation of innovation diffusion. Computational and Mathematical Organization Theory, Pittsburgh, v. 8, n. 4, p. 259-280, 2002.

MANSFIELD, E. Technical change and the rate of imitation. Econometrica, Nova York, v. 29, n. 4, p. 741-766, 1961.

MATSUYAMA, K. The rise of mass consumption societies. Journal of Political Economy, Chicago, v. 110, p. 1035 -1070, 2002.

METCALFE, J. S. Impulse and diffusion in the study of technical change. Futures, v. 13, n. 5, p. 347359, 1981.

MOLINA FILHO, J. Difusão de inovaçōes: críticas e alternativas ao modelo dominante. Cadernos de Ciência \& Tecnologia, Brasília, v. 6, n. 1, p. 101-115, 1989.

NANDAKUMAR, A. K.; BESWICK, J.; THOMAS, C. P.; WALLACK, S. S.; KRESS, D. Pathways of health technology diffusion: the United States and low-income countries. Health Affairs, Maryland, v. 28, n. 4, p. 986-995, 2009.

NOGUEIRA-CAMPOS, M. A.; GAMA, J. L. C. N. da; PINTO, M. de M. O processo de adoção e difusão de novas tecnologias nas edificaçōes: uma revisão bibliográfica. In: ENCONTRO NACIONAL DE ENGENHARIA DE PRODUÇÃO, 17. Anais... Rio de 
Janeiro: Associação Brasileira de Engenharia de Produção - Agepro, 2008. Disponível em: <http://www.abepro.org.br/biblioteca/enegep2008_tn_sto_087_569_11729.pdf>. Acesso em: 04 abr. 2016.

PAUliCS, V. A. T. Disseminação do Programa de Garantia de Renda Minima no Brasil (1991 - 1997), 2003, 170 f. Dissertação (Mestrado em Administração Pública e Governo) - FGV/ EAESP, São Paulo, 2003.

PEREIRA, L. C. B. A estratégia brasileira de desenvolvimento entre 1967 e 1973 . Revista de Administração Empresarial, São Paulo, v. 17, n. 4, p. 17-26, 1977.

RAHMANDAD, H.; STERMAN, J. Heterogeneity and network structure in the dynamics of diffusion: comparing agent-based and differential equation models. Management Science, Maryland, v. 54, n. 5, p. 998-1014, 2008.

ROGERS, E. M. Diffusion of innovations. 1. ed. New York: The Free Press, 1962.

ROSENBERG, N. Perspectives on technology. 1. ed. Cambridge: Cambridge University Press, 1976.

SAMPAIO, D. C.; HATEM, F. A relação entre efeitos de rede e ciclos de feedback - aplicação prática em uma rede de apostadores, 2013, 90 f. Monografia (Graduação em Engenharia de Produção) - Universidade Federal do Rio de Janeiro, Rio de Janeiro, 2013. Disponível em: <http://monografias.poli.ufrj.br/monografias/monopoli10008257.pdf >. Acesso em: 20 ago. 2017.

SCHUMPETER, J. A. A teoria do desenvolvimento econômico. 1. ed. São Paulo: Abril Cultural, 1912.

SILVERBERG, G. Modeling economic dynamics and technical change: mathematical approaches to self-organization and evolution. In: DOSI, G.; FREEMAN, C.; NELSON, R.; SILVERBERG, G.; SOETE, L. Technical change and economic theory. 1. ed. Londres: Pinter, 1988.

SOARES, D. de Q. Inovação tecnológica: desafios e perspectivas dos países subdesenvolvidos. Desigualdade \& Diversidade - Revista de Ciências Sociais da PUC-Rio, Rio de Janeiro, v. 8, p. 101-117, 2011.

STONEMAN, P. The economic analysis of technologial change. 1. ed. New York: Oxford University Press, 1983.

STRANG, D.; MACY, M. W. In search of excellence: fads, success stories, and adaptive emulation. American Journal of Sociology, Chicago, v. 107, n. 1, p. 147-182, 2001.

SULTAN, F; FARLEY, J. U.; LEHMANN, D. R. A meta-analysis of applications of diffusion models. Journal of Marketing Research, Chicago, v. 27, n. 1, p. 70-77, 1990. 
TELEVISOR. Wikipedia, a enciclopédia livre, [S.1., 2017?]. Disponível em: <https:// pt.wikipedia.org/wiki/Televisor>. Acesso em 20-08-2017.

TELLIS, G. J.; STREMERSCH, S.; YIN, E. The international takeoff of new products: the role of economics, culture, and country innovativeness. Marketing Science, Maryland, v. 22, n. 2, p. 188-208, 2002.

UNIVERSIDADE ESTADUAL DE MARINGÁ. História dos computadores no Brasil. Portal do Projeto Museu do Computador da UEM, [2017?]. Disponível em: <http://www. din.uem.br/museu/hist_nobrasil.htm>. Acesso em: 20 jul. 2017.

VAN DEN BULTE, C.; LILIEN, G. L. Bias and systematic change in the parameter estimates of macro-level diffusion models. Marketing Science, Maryland, v. 16, n. 4, p. 338-353, 1997.

VAN DEN BULTE, C.; STREMERSCH, S. Social contagion and income heterogeneity in new product diffusion: a meta-analytic test. Marketing Science, Maryland, v. 23, n. 4, p. 530-544, 2004.

VIEIRA FILHO, J. E. R.; SILVEIRA, J. M. F. J. da. Mudança tecnológica na agricultura: uma revisão crítica da literatura e o papel das economias de aprendizado. Revista de Economia e Sociologia Rural, Brasília, v. 50, n. 4, p. 721-742, 2012.

WHIRLPOOL. Whirlpool atinge a marca de 150 milhôes de lavadoras produzidas. Site institucional, Joinville, 2017. Disponível em: <https:/www.whirlpool.com.br/2011/09/ whirlpool-atinge-a-marca-de-150-milhoes-de-lavadoras-produzidas >. Acesso em: 18 ago. 2017.

WILSON, E. J. Liderança e difusão da internet: o caso do Brasil. DataGramaZero, João Pessoa, v. 1, n. 2, 2000. Disponível em: <http://basessibi.c3sl.ufpr.br/brapci/v/a/787>. Acesso em: 05 maio 2015.

ZETTELMEYER, F.; STONEMAN, P. L. Testing alternative models of new product diffusion. Economics of Innovation and New Technology, Montana, v. 2, p. 283-308, 1993. 
